\title{
Imaging and monitoring tailings dam walls with ambient seismic noise
}

\author{
T de Wit Institute of Mine Seismology, Australia \\ G Olivier Institute of Mine Seismology, Australia
}

This paper was originally published in the Proceedings of the 9th International Symposium on Rockbursts and Seismicity in Mines (RaSiM9). Acknowledgement is given to the University of Chile for their permission to republish this paper.

\begin{abstract}
Tailings dams are massive structures that are designed to contain the waste slurry remaining after processing ore at open pit and underground mines. These structures fail far more regularly than normal water storage dams, and in recent years catastrophic tailings dam failures have occurred, causing significant damage to the environment and even loss of life. To mitigate these catastrophic events in the future, there is an urgent need to develop cost-effective methods to monitor the structural stability of these constructions over time. The lack of current cost-effective subsurface imaging and monitoring methods prompted us to investigate whether ambient seismic noise can be used to image and detect internal changes in a tailings dam wall during a period of heavy rainfall.

We recorded three weeks of continuous seismic data with 10 short-period geophones at a tailings dam in Tasmania, Australia. Seismic interferometry was used on ambient noise to create virtual seismic sources. With these virtual source signals, small changes in seismic velocity were measured daily and compared to rainfall, seepage flow rates and fluid pore pressure. The observed velocity changes were driven by fluid saturation, groundwater level, increased loading from increased dam water level and a sudden increase in fluid pore pressure in a section of the dam wall. A further experiment was performed at a tailings dam in South Africa, where ambient noise surface wave tomography was used to image an area where seepage was identified. The results suggest that these relatively inexpensive methods can be used to monitor and locate small changes in the interior of tailings dam walls, providing a valuable tool for remotely monitoring the structural stability of tailings dam walls over time.
\end{abstract}

Keywords: seismic monitoring, imaging, interferometry

\section{Massive dams, massive risks}

Tailings dams are some of the largest man-made structures on earth, and one of the most technically challenging areas for geotechnical engineers to maintain and monitor. Over the last few decades, many tailings dam failures have occurred, and it is estimated that approximately two to five major failures occur per year (Davies 2002). The failure rate of these structures is more than 100 times higher than normal water storage dams (Azam \& Li 2010). This is due to the relatively loose regulations surrounding these structures in developing countries and due to the cost-saving methods that are used when these structures are designed.

The most common tailings dam design is called the upstream method. In this method, the tailings next to the dam wall are allowed to dry and these solidified tailings are then used as the foundation for subsequent raises (or lifts) to accommodate more tailings. This method is attractive from an economic standpoint, as it requires the least amount of earthmoving to increase the capacity of the dam. However, walls built using this method are also the most likely to fail (Breitenbach 2010). This wall design method is particularly susceptible to soil liquefaction due to shaking from earthquakes, mine blasts, and other vibrations (Fell 1992; Martin 1999), and consequently this design method is banned in some earthquake-prone countries such as Chile and Peru (Breitenbach 2010). 
In November 2015, the Fundão tailings dam wall in Brazil suddenly failed. This incident is considered to be one of the largest environmental disasters in recent years (de Oliveira Neves et al. 2016). Recent results indicate that the failure of the dam wall may have been triggered by a sequence of small-magnitude earthquakes (Agurto-Detzel et al. 2016). This could suggest that the dam wall was in an already weakened state at this time, as the largest seismic event in this sequence had a relatively small moment magnitude of $M_{w}=2.6$. The possibility that such a small seismic sequence triggering such a catastrophic disaster is concerning for numerous other tailings dams around the world and emphasises the need to monitor the structural stability of the wall over time in order to be aware of degradation and weakening, and to investigate the mechanisms of failure.

In Australia, there are regulations in place to ensure that many tailings dams are equipped with monitoring equipment to understand the long-term response of the internal wall structure to the rising tailings level and weathering. Additionally, the short-term response of the wall to external factors like heavy rainfall or earthquakes are of interest since it is known that these factors can contribute to failures (Azam \& Li 2010). Current monitoring methods appear to mostly address the long-term behaviour of the wall. Methods to monitor the short-term behaviour of the wall in response to external factors include ground-based radar. These methods are only employed when a specific concern is raised, in large part due to the significant costs involved in installing and operating these methods.

Borehole piezometers are used to monitor the pore pressures and groundwater level inside the dam walls, since gradual increases in these parameters can cause static liquefaction (Martin \& McRoberts 1999; Eckersley 1990). In some cases, radars and/or high-resolution cameras are used to monitor small deformations of the dam walls. Unfortunately, these methods measure surface perturbations and are not capable of detecting internal changes in the walls. Crucially, the delays between the time that surface perturbations become detectable and the time of failure are often not sufficient for early warning (Fell et al. 2003). Other failure mechanisms, like internal erosion (or piping failure) are monitored with flow meters that measure the cumulative seepage at the toe of the embankment but also do not give much advance warning. Another concern with current monitoring technology is their poor performance during heavy rainfall. Small deformations on the dam wall become very difficult to detect due to the fluid on the surface of the wall. Similarly, seepage flow rates are hard to interpret during heavy rainfall due to the flow of the rain down the embankment contaminating the measurements. These limitations are unfortunate since heavy rain has been known to be a significant contributing factor to tailings dam wall failure (Azam \& Li 2010).

\section{$2 \quad$ Turning seismic noise into signal}

In the last decade, ambient seismic noise interferometry has been used to monitor the time-dependent behaviours of volcanoes (Sens-Schönfelder \& Wegler 2006; Duputel et al. 2009; Brenguier et al. 2008a), landslides (Mainsant et al. 2013), underground mines (Olivier 2015a; Olivier \& Brenguier 2016), geothermal reservoirs (Obermann et al. 2015), active faults zones (Brenguier et al. 2008b; Taira et al. 2015) and other environments. Recent laboratory experiments have even shown that this method is able to detect internal erosion (piping failure) in earthen embankments (Planès et al. 2015). This method essentially uses ambient seismic vibrations to create virtual seismic sources (Curtis et al. 2006).

Since the seismograms from these virtual seismic sources contain information about the entire medium that they pass through, this method is able to detect very small changes in the seismic velocity of the medium. Changes in seismic velocity are induced by stress changes (Nur 1971), fluid saturation (O'Connell \& Budiansky 1974), damage (Lockner et al. 1977) and fluid pore pressure (Brenguier et al. 2014). If we are able to use seismic interferometry to measure small changes in seismic velocity in the dam wall, we should be able to infer changes in these properties over time and improve our understanding of the structural stability of the dam wall.

The limitations of current monitoring methods and the success of seismic interferometry in other applications encouraged us to investigate whether this method can be used to detect internal changes in a tailings dam wall during a period of heavy rainfall. 


\section{Princess Creek tailings dam}

Princess Creek tailings dam is located near Queenstown in Tasmania, Australia (Figure 1). The dam wall was constructed using the downstream method and is designed to house the tailings from a nearby copper mine. This method uses sequential lifts in the downstream direction to increase the capacity of the dam. However, unlike the upstream method, solidified tailings are not used when constructing these lifts. As a result, the method requires significantly more earthmoving to increase the capacity of the dam, but the construction is generally considered to be more reliable than with the upstream method. Princess Creek has not exhibited any signs of structural instability, but the area has an annual rainfall of more than 2,400 $\mathrm{mm}$ which means that the dam wall is well instrumented and monitored for signs of deterioration or internal changes.

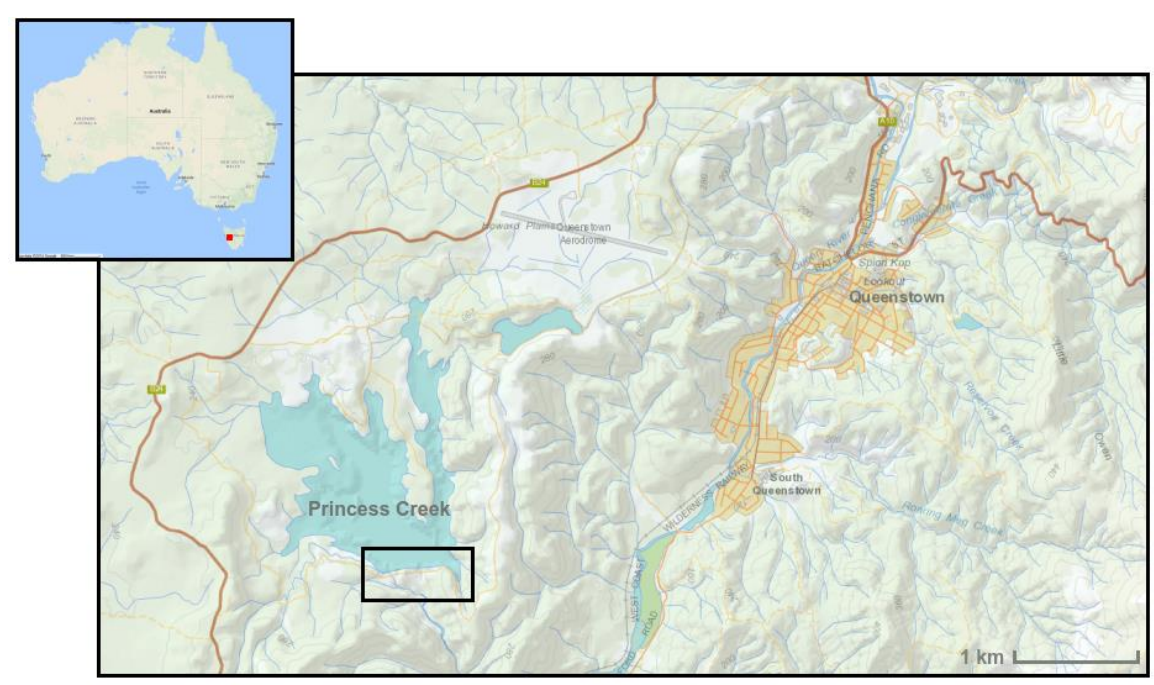

Figure 1 Location of Princess Creek tailings dam in Tasmania, Australia. The dam wall is located on the southeastern side of the dam, indicated by the rectangle

The crest of the embankment is roughly $400 \mathrm{~m}$ long and the dam wall is roughly $50 \mathrm{~m}$ high. Six vibrating wire piezometers are used to monitor the pore pressure and groundwater level over time, while $V$-notch flow meters are installed at the toe of the embankment to detect any anomalous seepage. The water level in the lake and the daily rainfall are monitored while biweekly visual inspections are performed to identify any signs of seepage. These signs include patches of vegetation growth and/or visible water on the surface of the wall, even in the absence of rain.

\section{$4 \quad$ Data}

Continuous seismic data were recorded with $104.5 \mathrm{~Hz}$ geophones (four uniaxial and six triaxial) for 18 to 26 days at a sampling rate of 400 samples per second. The uniaxial geophones (numbers one to four in Figure 2) recorded data from 19 April to 15 May 2016, while the triaxial geophones recorded data up to 5 May 2016. The geophones were installed in holes $40 \mathrm{~cm}$ below surface to shield them from wind and rain. The geophones were connected to standalone data acquisition units, powered with $12 \mathrm{~V}$ batteries and time synchronised by GPS. The locations of the seismic sensors are shown in Figure 2, along with the locations of the V-notch flow meters and the vibrating wire piezometers. By comparing the spatio-temporal variations in the ambient seismic noise field with auxiliary information, it seems as if most of the seismic energy recorded by the geophones is generated by the flowing water from the decant system (see bottom left in Figure 2) and wind waves on Princess Creek lake. 


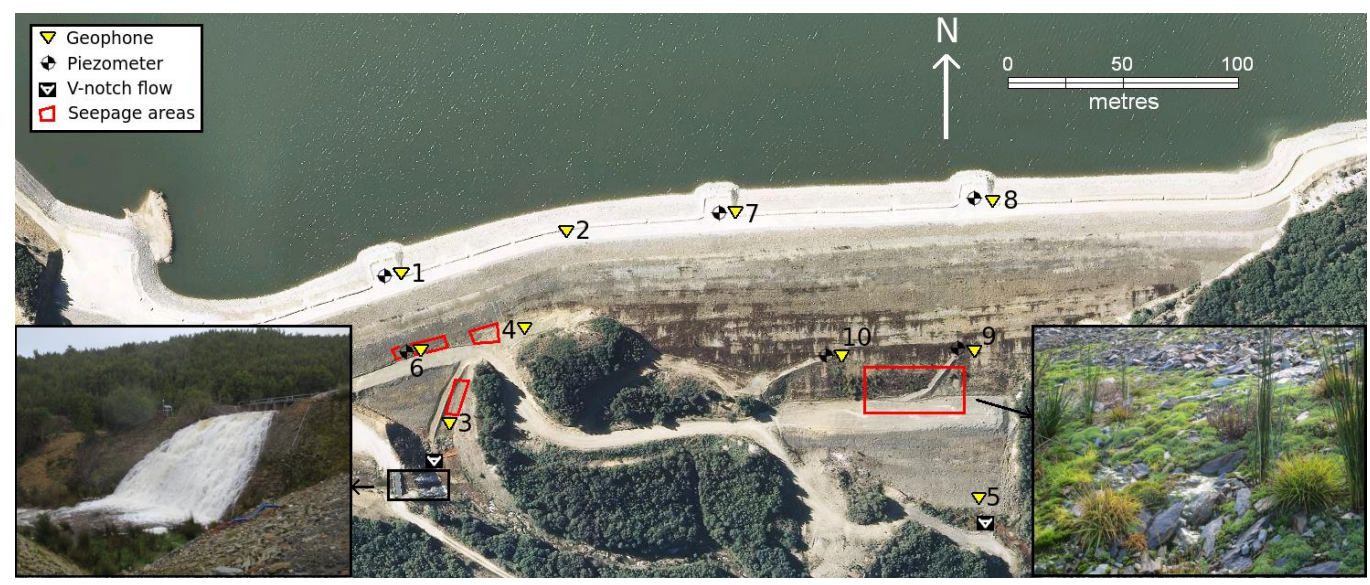

Figure 2 Location of geophones, piezometers and V-notch flow meters on the dam wall. Sensors one to four are uniaxial and sensors five to ten are triaxial. Areas where visible seepage was identified during the installation are indicated in red. The bottom right inset shows one of these seepages. The bottom left inset shows the flowing water from the decant overflow system

The geophones were placed so that the instruments covered the entire wall and so that they were optimally orientated towards the decant overflow system. This system is used to control the water level of the lake. During the data recording period, the system produced a steady stream of flowing water. During installation, a few areas were identified where seepage is observed on the wall. This seepage is visible as water on the surface of the wall and is often accompanied by a patch of irregular vegetation growth (Figure 2).

The size and seepage rate of these areas are constantly monitored to detect any signs of internal erosion (piping failure) or increased groundwater level, especially during times of heavy rainfall. During the time in which we recorded data, it rained more than $450 \mathrm{~mm}$ and the lake level increased by more than $1 \mathrm{~m}$. Most of this rainfall occurred after 8 May 2016, which means that the triaxial geophones did not record data during this period. We will therefore only consider data recorded by the four uniaxial geophones for this study.

\section{$5 \quad$ Constructing virtual seismic sources}

The pre-processing steps to construct virtual sources from ambient seismic wavefields have become reasonably standard over the years (e.g. Lecocq et al. 2014). However, some additional steps are required in the presence of non-stable seismic sources. In particular, the use of a selection filter is essential to construct stable virtual sources with seismic noise that exhibited spatio-temporal variations (Olivier et al. 2015b; Nakata et al. 2015). A brief outline of the steps is given below.

Continuous seismic data is split into 20 second sections. These sections are spectrally whitened between 5 and $120 \mathrm{~Hz}$ and one-bit normalised in order to enhance the contributions of weak sources. These data sections are then cross-correlated with data sections from other sensors. For 10 seismic sensors, there are 45 sensor pairs. A selection criterion is then applied to the cross-correlation function for each sensor pair to determine whether it is added to a stack to represent the daily virtual source for each sensor pair. All the daily cross-correlation functions for one station pair are shown in Figure 3. Most of the energy in the crosscorrelation functions appear at positive lag times due to the non-isotropically distributed noise sources. For this station pair, the seismic noise generated by the flowing water from the decant system dominates the noise records. However, the daily cross-correlation functions are remarkably stable over time. 


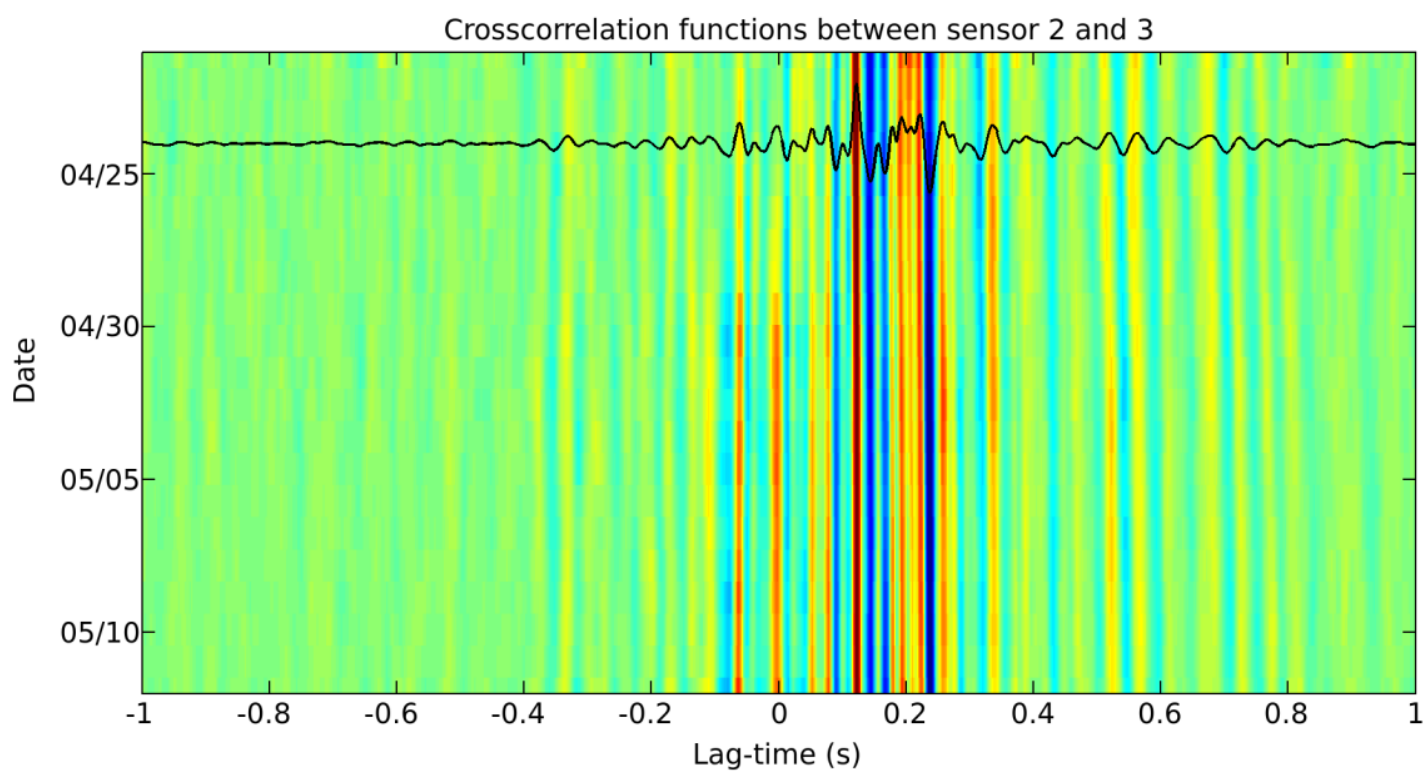

Figure 3 Daily normalised cross-correlation functions for one station pair. The stack of all daily correlation functions is shown in black. The processing scheme we applied succeeds in recovering stable daily cross-correlation functions

\section{Measuring changes in seismic velocity}

After the daily virtual sources are constructed, changes in seismic velocity are calculated by comparison with a reference virtual seismic source signal. Typically, only the multiply scattered part (coda) of the virtual source signal is considered when this measurement is made and apparent changes in the direct arrivals are neglected. This is done for two reasons. Firstly, the coda part of the virtual source signal is more robust than the direct arrival with regard to changes of the seismic noise sources (e.g. Froment et al. 2010; Colombi et al. 2014). Therefore, ignoring the direct arrival reduces the bias introduced by changes in seismic noise sources. Secondly, the multiply scattered waves sample the medium for a longer time period and, therefore, small changes in velocity become clear in the coda even when no change can be measured in the direct arrivals (Figure 4). The changes that are measured in the coda mostly represent changes in shear wave velocity (Snieder 2006).

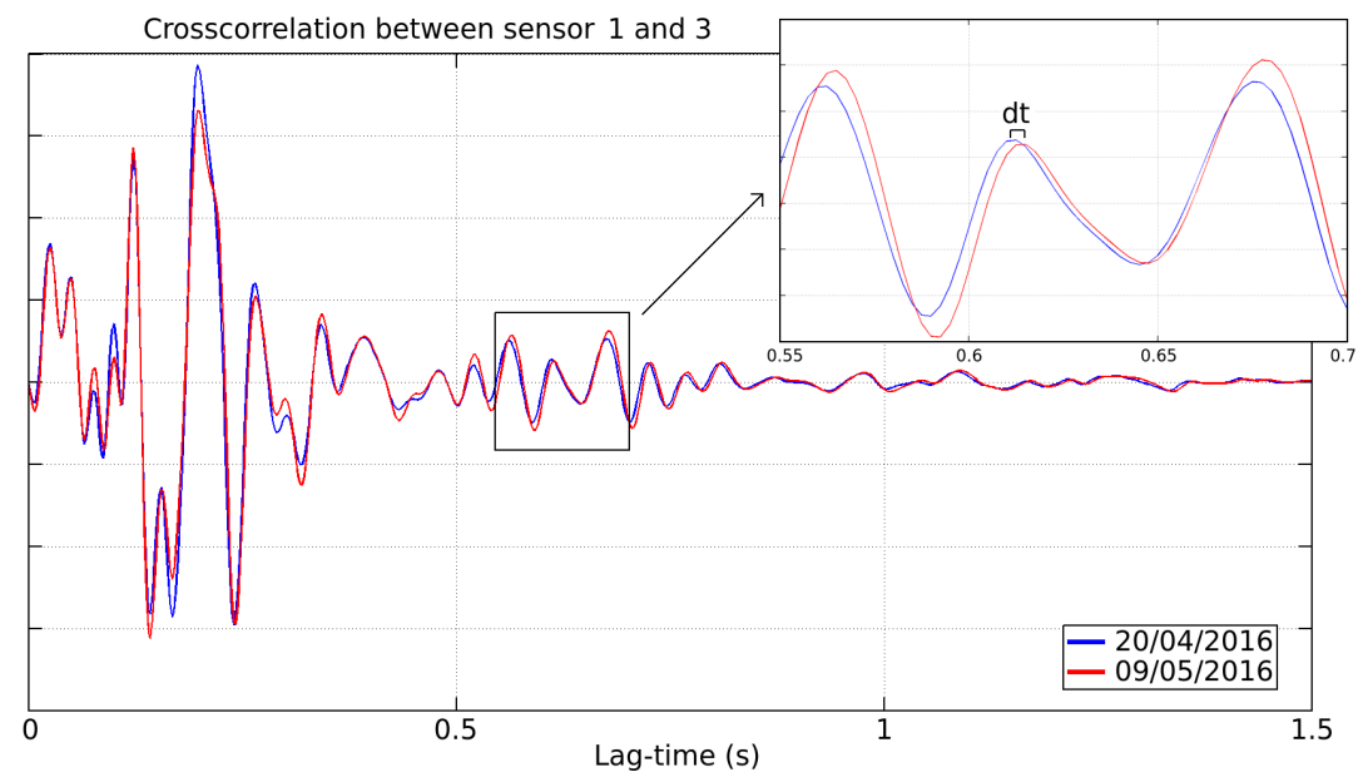

Figure 4 Virtual source signals generated with ambient seismic noise correlations on 20 April and 9 May 2016. In the direct arrival, there are no clear changes in seismic velocity, whereas a large decrease in velocity is clear in the coda 
Calculating the relative velocity changes is carried out by either using the doublet (Poupinet et al. 1984; Clarke et al. 2011; Lecocq 2014) or stretching (Daskalakis et al. 2016) method. Under ideal circumstances, these methods give the same result, but in some cases one of these methods might be better suited than the other. For the measurements at Princess Creek, it was found that the stretching method was more appropriate than the doublet method due to the large fluctuations in seismic velocity - the doublet method can underestimate large changes in seismic velocity due to period skipping in the coda of the correlation functions. The doublet method is better suited when small changes need to be measured and when cross-correlation functions become decoherent over time.

\section{$7 \quad$ Results}

Daily seismic velocity variations were calculated for each station pair with the stretching method. These changes were compared to seepage flow rates, daily rainfall and the water level of the lake. The comparison is shown in Figure 5. Two remarkable processes can be seen in Figure 5, acting on different time scales.

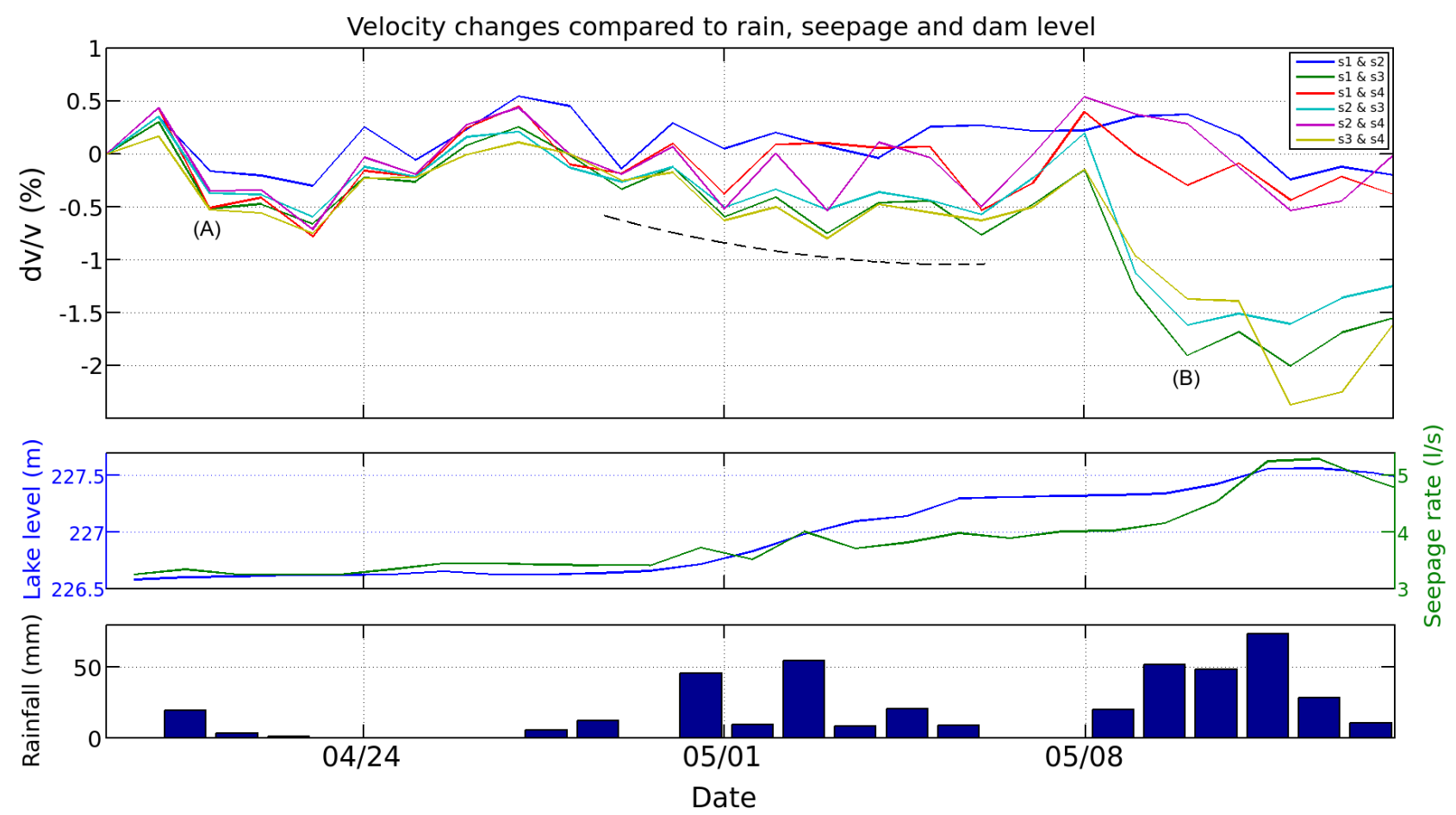

Figure 5 Relative velocity variations for six station pairs from 19 April to 14 May 2016 compared to seepage flow rates, lake level and daily rainfall

Two remarkable features can be seen in the velocity variations: (A) Decreases in velocity, probably due to fluid saturation of the soil during heavy rain fall; and, (B) Sudden permanent decrease in seismic velocity for some station pairs after 8 May 2016.

(A) During days that record more than $15 \mathrm{~mm}$ rainfall (19 April for instance), a decrease in seismic velocity of the order of $0.3 \%$ is seen for all pairs. A decrease in velocity in response to rainfall is observed for two possible reasons. Firstly, the increased saturation of the soil causes an increase in bulk density which in turn decreases the S-wave velocity (Smith et al. 2003). Secondly, the saturation increases the fluid pore pressure which in turn opens microcracks and flaws that tend to lower the velocity (Mavko et al. 2009). After the rainfall subsides, the soil becomes less saturated and the velocities at least partially recover.

(B) Secondly, and most notably, there is a sudden decrease in velocity of more than $2 \%$ on 9 May 2016 for the yellow, green and cyan station pairs. As shown in Figure 5, the area where the large decrease in velocity is observed is in good agreement with the area where potentially increased visible seepage was identified. The piezometer readings closest to this area registered an increase in pore pressure of $2.6 \mathrm{kPa}$ and an 
increase in groundwater level of $30 \mathrm{~cm}$, which is the largest increase in pore pressure and groundwater level measured of the six piezometers in the wall. The fact that we observe a sudden velocity decrease in the area where visual observations of increased seepage were made and a significant change in fluid pore pressure is measured could be a good indication that a permanent subsurface change occurred on 9 May due to an extended period of heavy rain. According to the engineers in charge of monitoring the dam, it is likely that seepage originated at the contact between the button-shaped local topography and the wall, which is also in good agreement with the location of the velocity changes (Figure 6).

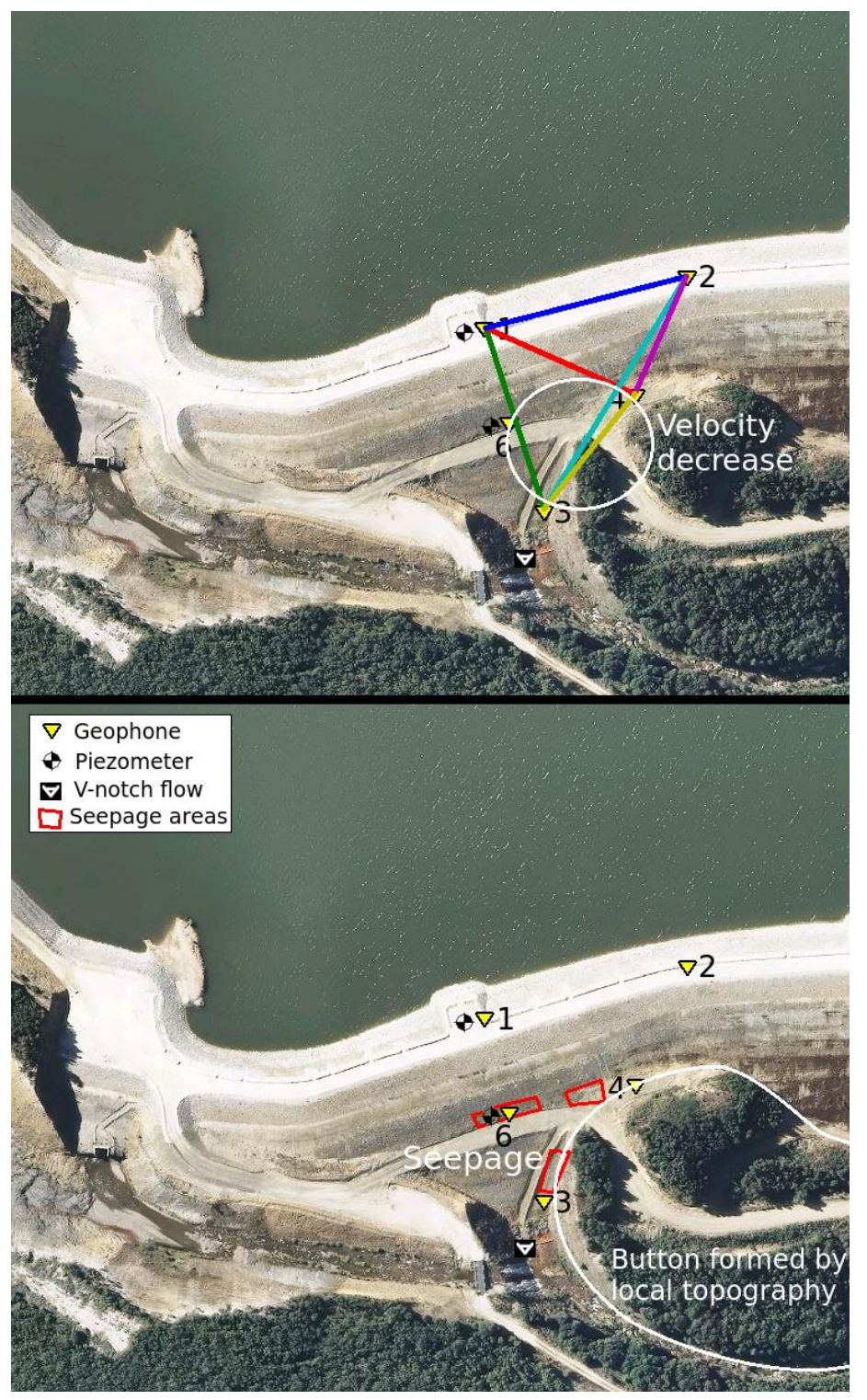

Figure 6 Comparison of the area where a significant velocity decrease was detected from 8-10 May 2016 compared to the areas where increased seepages were visually identified between the first visit on 19 April 2016 and the next visit on 24 May 2016

Another interesting observation is the slow decrease in seismic velocity of about $0.7 \%$ that is noticeable from 26 April to 5 May 2016 (indicated by the dotted line in Figure 5) for the three station pairs (yellow, green and cyan) that sample the lower parts of the wall. These pairs eventually experienced a sudden decrease on 9 May 2016 as described in (B). This observation could indicate that the sudden subsurface change that occurred on 9 May 2016 started off gradually on 16 April 2016 as the lake level increased. 


\section{$8 \quad$ What does this mean?}

Tailings dams are required to contain the waste slurry remaining after processing ore, but these structures fail far more regularly than normal water storage dams. The lack of cost-effective methods to monitor these structures indicate a critical need to research and develop new methods to monitor the time-dependent behaviour of these structures. Recent advances in seismic interferometry have enabled us to use the background noise to create virtual seismic sources at the sensor positions. This method has the potential to be a cost-effective way to monitor the interior structure of tailings dam walls, since it can enable us to detect small changes beneath the surface of the walls with standard passive microseismic monitoring equipment.

We recorded continuous seismic data with 10 short-period geophones for 25 days during a period of heavy rainfall at a tailings dam in Tasmania. Even though the dam has not experienced any structural concerns, and has been constructed according to the strict Australian standards, it is a good location to conduct an initial experiment since the dam wall is well instrumented and monitored, and the area has an annual rainfall of more than $2,400 \mathrm{~mm}$. The results of the experiment indicate that the ambient seismic noise recorded by the geophones is well suited to constructing regular and robust virtual seismic sources. Changes in seismic velocity around these virtual seismic sources were measured by using the stretching method. The achieved relative velocity variations are sensitive enough to measure and locate increases in the fluid saturation of the soil due to rain. The method also indicated some permanent subsurface changes in the dam wall in locations consistent with observations of increased seepage occurring between the contact of local topography and the earthen dam wall. This in situ result is consistent with the recent laboratory study of Planès et al. (2015) in which ambient seismic noise was used to detect permanent subsurface degradation of a small-scale earthfill wall as new piping failures were created.

This small study has indicated that it is possible to monitor the subsurface condition of an earthfill dam wall using relatively inexpensive microseismic monitoring stations and ambient seismic noise. A few longer-term studies using permanent arrays of seismic sensors are now being planned.

\section{Acknowledgement}

We thank Geoff Cordery, Rebecca Ritchie, Col Brain and Matt Daley for their help to set up, operate and interpret the experiment, as well as Thomas Planès for the useful discussion. The manuscript was improved by comments from Tracy Stark, Yohei Nishitsuji and Olaf Goldbach. We also thank Copper Mines of Tasmania for allowing us to perform the experiment at Princess Creek, GHD for giving us access to auxiliary data and AEON at the Nelson Mandela Metropolitan University, South Africa for providing data acquisition units.

\section{References}

Agurto-Detzel, H, Bianchi, M, Assumpção, M, Schimmel, M, Collaço, B, Ciardelli, C, Barbosa, JR \& Calhau, J 2016, 'The tailings dam failure of 5 November 2015 in SE Brazil and its preceding seismic sequence', Geophysical Research Letters, vol. 43.

Azam, S \& Li, Q 2010,' Tailings dam failures: A review of the last one hundred years', Geotechnical News, vol. 28, pp. 50-54.

Breitenbach, AJ 2010, 'Overview: tailings disposal and dam construction practices in the 21st century', Proceedings of the 14th International Conference on Tailings and Mine Waste, CRC Press, Leiden, pp. 49-57.

Brenguier, F, Campillo, M, Hadziioannou, C, Shapiro, N, Nadeau, R \& Larose, E 2008b, 'Postseismic relaxation along the San Andreas fault at Parkfield from continuous seismological observations', Science, vol. 321, no. 5895, pp. 1478-1481.

Brenguier, F, Campillo, M, Takeda, T, Aoki, Y, Shapiro, N, Briand, X, Emoto, K \& Miyake, H 2014, 'Mapping pressurized volcanic fluids from induced crustal seismic velocity drops', Science, vol. 345, no. 6192, pp. 80-82.

Brenguier, F, Shapiro, NM, Campillo, M, Ferrazzini, V, Duputel, Z, Coutant, O \& Nercessian, A 2008a, 'Towards forecasting volcanic eruptions using seismic noise', Nature Geoscience, vol. 1, no. 2, pp. 126-130.

Clarke, D, Zaccarelli, L, Shapiro, N \& Brenguier, F 2011, 'Assessment of resolution and accuracy of the moving window cross spectral technique for monitoring crustal temporal variations using ambient seismic noise', Geophysical Journal International, vol. 186 , no. 2, pp. 867-882

Colombi, A, Chaput, J, Brenguier, F, Hillers, G, Roux, P \& Campillo, M 2014, 'On the temporal stability of the coda of ambient noise correlations', Comptes Rendus Geoscience, vol. 346, no. 11, pp. 307-316.

Curtis, A, Gerstoft, P, Sato, H, Snieder, R \& Wapenaar, K 2006, 'Seismic interferometry - turning noise into signal', The Leading Edge, vol. 25, pp. 1082-1092. 
Daskalakis, E, Evangelidis, CP, Garnier, J, Melis, NS, Papanicolaou, G \& Tsogka, C 2016, 'Robust seismic velocity change estimation using ambient noise recordings', Geophysical Journal International, vol. 205, no. 3, pp. 1926-1936.

Davies, MP 2002, 'Tailings impoundment failures: are geotechnical engineers listening', Geotechnical News, vol. 20, no. 3, pp. 31-36. de Oliveira Neves, AC, Nunes, F, de Carvalho, F \& Fernandes, G 2016, 'Neglect of ecosystems services by mining, and the worst environmental disaster in Brazil', Natureza \& Conservação, vol. 14, no. 1, pp. 24-27.

Duputel, Z, Ferrazzini, V, Brenguier, F, Shapiro, N, Campillo, M \& Nercessian A 2009, 'Real time monitoring of relative velocity changes using ambient seismic noise at the Piton de la Fournaise volcano (La Réunion) from January 2006 to June 2007', Journal of Volcanology and Geothermal Research, vol. 184, pp. 164-173.

Eckersley, D 1990, 'Instrumented laboratory flowslides', Géotechnique, vol. 40, no. 3, pp. 489-502.

Fell, R, MacGregor, P \& Stapledon, D 1992, Geotechnical Engineering of Embankment Dams, A.A. Balkema, Rotterdam.

Fell, R, Wan, CF, Cyganiewicz, J \& Foster, M 2003, 'Time for development of internal erosion and piping in embankment dams', Journal of geotechnical and geoenvironmental engineering, vol. 129, no. 4, pp. 307-314.

Froment, B, Campillo, M, Roux, P, Gouedard, P, Verdel, A \& Weaver, RL 2010, 'Estimation of the effect of non-isotropically distributed energy on the apparent arrival time in correlations', Geophysics, vol. 75, no. 5, pp. 85-93.

Lecocq, T, Caudron, C \& Brenguier, F 2014, 'MSNoise, a python package for monitoring seismic velocity changes using ambient seismic noise', Seismological Research Letters, vol. 85, no. 3, pp. 715-726.

Lockner, DA, Walsh, JB \& Byerlee, JD 1977, 'Changes in seismic velocity and attenuation during deformation of granite', Journal of Geophysical Research, vol. 82, pp. 5374-5378.

Mainsant, G, Larose, E, Bronnimann, C, Jongmans, D, Michoud, C \& Jaboyedoff, M 2013, 'Ambient seismic noise monitoring of a clay landslide: toward failure prediction', Journal of Geophysical Research, vol. 117, no. F01030, http://dx.doi.org/10.1029/ 2011JF002159

Martin, TE \& McRoberts, EC 1999, 'Some considerations in the stability analysis of upstream tailings dams', Proceedings of the Sixth International Conference on Tailings and Mine Waste, A.A. Balkema, Rotterdam, pp. 287-302.

Mavko, G, Mukerji, G \& Dvorkin, J 2009, The Rock Physics Handbook: Tools for Seismic Analysis of Porous Media, Cambridge University Press, Cambridge.

Nakata, N, Chang, JP, Lawrence, JF \& Boué, P 2015, 'Body wave extraction and tomography at Long Beach, California, with ambient-noise interferometry', Journal of Geophysical Research: Solid Earth, vol. 120, no. 2, pp. 1159-1173.

Nur, A 1971, 'Effects of stress on velocity anisotropy in rocks with cracks', Journal of Geophysical Research, vol. 76, no. 8, pp. 2022-2034.

Obermann, A, Kraft, T, Larose, E \& Wiemer, S 2015, 'Potential of ambient seismic noise techniques to monitor reservoir dynamics at the St. Gallen geothermal site (Switzerland)', Journal of Geophysical Research, vol. 120, no. 6, pp. 4301-4316.

O'Connell, RJ \& Budiansky, B 1974, 'Seismic velocities in dry and saturated cracked solids', Journal of Geophysical Research, vol. 79, pp. 5412-5426.

Olivier, G, Brenguier, F, Campillo, M, Lynch, R \& Roux, P 2015a, 'Body-wave reconstruction from ambient seismic noise correlations in an underground mine', Geophysics, vol. 80, no. 3, pp. KS11-KS25.

Olivier, F, Brenguier, M, Campillo, P, Roux, NM, Shapiro \& Lynch, R 2015b, 'Investigation of coseismic and postseismic processes using in situ measurements of seismic velocity variations in an underground mine', Geophysical Research Letters, vol. 42, no. 21, pp. 9261-9269.

Olivier, G \& Brenguier, F 2016, 'Interpreting seismic velocity changes observed with ambient seismic noise correlations', Interpretation, vol. 4, no. 3, pp. SJ77-SJ85.

Planés, T, Mooney, M, Rittgers, J, Parekh, M, Behm, M \& Snieder, R 2015, 'Time-lapse monitoring of internal erosion in earthen dams and levees using ambient seismic noise', Géotechnique, vol. 66, no. 4, pp. 301-312.

Poupinet, G, Ellsworth, WL \& Frechet, J 1984, 'Monitoring velocity variations in the crust using earthquake doublets: an application to the Calaveras Fault, California', Journal of Geophysical Research: Solid Earth, vol. 89, no. B7, pp. 5719-5731.

Sens-Schönfelder, C \& Wegler, U 2006, 'Passive image interferometry and seasonal variations of seismic velocities at Merapi Volcano, Indonesia', Geophysical Research Letters, vol. 33, no. 21, https://dx.doi.org/10.1029/2006GL027797

Smith, TM, Sondergeld, CH \& Rai, CS 2003, 'Gassmann fluid substitutions: A tutorial', Geophysics, vol. 68, no. 2, pp. 430-440.

Snieder, R 2006, 'The theory of coda wave interferometry', Pure and Applied Geophysics, vol. 163, no. 2-3, pp. 455-473.

Taira, T, Brenguier, F \& Kong, Q 2015, 'Ambient noise based monitoring of seismic velocity changes associated with the $2014 \mathrm{Mw} 6.0$ South Napa earthquake', Geophysical Research Letters, vol. 42, no. 17, pp. 6997-7004. 
